\title{
El dominio forense en el Diccionario castellano de Terreros ${ }^{1}$
}

\author{
Maria do Carmo Henríquez Salido \\ Universidade de Vigo
}

\section{INTRODUCCIÓN}

Al margen del trabajo de la Academia, cuyo prestigio le permitió que su diccionario llegase a la tercera edición en el año 1791, al margen de los ambiciosos proyectos lexicográficos de Mayans y de los repertorios de carácter bilingüe o multilingüe, el "único diccionario general de la lengua española que, aparte los de la Academia, se compila en España durante el Siglo de las Luces" (Álvarez de Miranda 1992: 559), es el DCCA del P. Esteban de Terreros y Pando, y el primero que manifiesta de modo explícito dar entrada a "180.000 términos" de la lengua común, de las ciencias y de las artes. En la obra, de gran interés lexicográfico y lexicológico, es evidente "el carácter acumulativo de la nomenclatura" (Echevarría 2001: 371), el carácter poco selectivo del léxico y la desigual elaboración de los artículos lexicográficos.

El DCCA, "un diccionario general de la lengua enriquecido con cuantos términos específicos de las artes y técnicas pudo allegar el autor" (Alvar Ezquerra 1987, I: VI), menos elaborado que el $D A$, es, ante todo, "un diccionario de lengua, del "común del idioma" y no un diccionario de tecnicismos" (Azorín 2000: 209) o "un diccionario de especialidad" (Ahumada 2000: 88). Fue publicado después de la muerte del autor (1782), pero sus tres primeros volúmenes estuvieron concluidos

1 Este trabajo se inscribe en el marco del Proyecto de investigación "Jurisprudencia, léxico y terminología jurídica" de la "Consellería da Presidencia e Administración Pública da Xunta de Galicia" (PGDIT01PXI30202PR), que se ha llevado a cabo en el Departamento de Lengua Española de la Universidad de Vigo, con la colaboración de Enrique De No Alonso-Misol, magistrado de la Audiencia Nacional. Para citar el Diccionario castellano con las voces de ciencias y artes y sus correspondientes en las tres lenguas francesa, latina e italiana, utilizamos la sigla DCCA; para el Tesoro de la lengua castellana o española, usamos la abreviación Tesoro y para el primer diccionario académico la sigla $D A$. No damos pormenores bibliográficos del Tesoro de Covarrubias, ni del $D A$, ni del $D C C A$ por suponer que son bien conocidos. Para la biografía de Terreros y su obra remitimos, específicamente, a Ahumada (2000), Alvar Ezquerra (1987), Álvarez de Miranda (1992, 2001), Azorín (2000), Echevarría Isusquiza (2001), García Platero (2003) y Seco (2003). En los ejemplos y textos citados modernizamos la acentuación, pero respetamos la ortografía. 
prácticamente en 1765 (Álvarez de Miranda 1992: 563), dato fundamental, porque el cuerpo del diccionario hay que situarlo en los inicios del reinado de Carlos III y no en las dos últimas décadas del siglo XVIII, lo cual aconseja establecer cotejos con las obras y fuentes anteriores a esta fecha y no, por ejemplo, con la segunda o la tercera edición del diccionario académico.

Si tomamos en consideración las palabras de nuestro diccionarista contenidas en el "Prólogo" (Terreros 1987, I: I-XXXIV), en lo que afecta a los dominios forense y jurídico, se confeccionó a partir de las contribuciones procedentes de los "sabios Españoles", que han dado prestigio a "la Jurisprudencia", y tomó como base "multitud de códigos y papeles antiguos" (como las Leyes de las Partidas) e "innumerables escrituras y papeles de pertenencias y derechos que se hallan en nuestros Archivos". El "objeto principal de su trabajo" es añadir a las voces comunes del idioma "otras no menores de las ciencias y artes", como el Derecho Civil y Canónico, pero sin perder de vista que la "colección de voces", que desea dar al público, comprende "aquellas que se hallan comúnmente en Autores clásicos, puros y autorizados" y "el de las ciencias y artes mecánicas y liberales" (Terreros 1987, I: IIVII). El jesuita demuestra especial interés por dar acogida en su trabajo tanto a la terminología correspondiente a muchos oficios y actividades artesanales, o sea, las voces designadoras de los trabajos o actividades que se hacen con "las manos", que obtiene incluso a través de una investigación directa, como a las unidades léxicas con valor especializado, caracterizadoras de las diferentes ramas del conocimiento científico, como es el caso de las que en la actualidad el DRAE-2001 distingue con la marca diatécnica Der. ('derecho'). Sería "prolijo enumerar las disciplinas que están representadas en el diccionario a través de su léxico" y si se tomasen las profesiones "que aparecen en el diccionario obtendríamos, con seguridad, una completísima relación que reflejaría con bastante fidelidad el panorama laboral de nuestro siglo XVIII" (Alvar Ezquerra 1987, I: XIII-XIV).

El $D C C A$ supera el número de entradas y de entradillas del $D A$, al que toma como referente, pero en ningún modo rebasa y ni siquiera alcanza la cifra de tecnicismos forenses, que hemos documentado en el primer diccionario académico (Henríquez 2004). Nuestro lexicógrafo hace una profunda revisión: suprime esta particularidad de uso casi en la mitad de los ejemplos y, aunque incorpora voces o acepciones no documentadas en "la gran obra pionera de la Academia", el resultado final, como analizaremos en este estudio, es que de las 458 voces y acepciones, que en la magna obra académica contienen en el interior del artículo lexicográfico observaciones sobre su uso en "el estilo forense", Terreros, siempre y cuando nuestro recuento sea exacto, puesto que obtenemos los datos a partir de la lectura del texto, las reduce prácticamente a la mitad.

El $D C C A$ suscita, por todo lo dicho, dos problemas que pueden ser objeto de controversia. El primero tiene que ver con el debate existente sobre si el $D A$, si- 
guiendo el ejemplo de la Academia Francesa que rechazaba los "términos de artes y ciencias" (Haensch 1997: 21), registra solo las voces de las "artes liberales y mechánicas" "que han parecido más comunes y precisas al uso, y que se podrían echar de menos" (Real Academia Española, Prólogo, 1990, I: v), es decir, dedica escasa atención al vocabulario científico y técnico, o si hay que acabar con este tópico y sostener que "el Diccionario de Autoridades incluye miles de tecnicismos, a pesar de lo que se diga en el prólogo del mismo" (Gutiérrez Rodilla 2003: 458). Y el segundo está relacionado con la vieja discusión respecto a si los diccionarios monolingües deben seleccionar como entradas, o incluir como acepciones, voces de las lenguas especializadas, y en el caso de que así sea, dónde debe estar el límite entre el léxico general y el léxico especializado, o si se debe considerar la existencia de diversos niveles (Catalá 2003: 517).

En este estudio nos proponemos como objetivos: (a) analizar la estructura de los artículos del diccionario, en los que el propio autor inserta en el enunciado definitorio fórmulas o notas diversas, que distinguen el uso de determinadas piezas léxicas en el dominio forense, y describir los diferentes modelos utilizados, para expresar esta concreta dimensión diasistemática; y, (b) hacer un estudio comparativo con el $D A$, la "fuente principal del repertorio de Terreros" (Alvar Ezquerra 1987, I: x), para, en primer lugar, comentar las voces y acepciones que no selecciona, las que no distingue, porque podrían haberse extendido al uso frecuente $u$ ocasional de la lengua común y culta, y las que no incluye en el dominio forense, por haberlas trasladado a otros campos del saber y de las actividades profesionales como la Jurisprudencia, el Derecho, los Tribunales o las Leyes, y, en segundo lugar, mostrar las que conservan esta particularidad de uso documentada en el $D A$ y las entradas y entradillas nuevas, que el jesuita incorpora a "esta arte liberal" ("la que se exerce con solo el ingenio", $D A$, s. v. liberal) en el período de tiempo comprendido desde 1745 a 1767.

\section{EL DOMINIO FORENSE}

De acuerdo con la definición del $D C C A$, por dominio forense hay que entender "lo que pertenece al foro, o tribunal de algún juez", es decir, voces procedentes de la actividad profesional de los abogados y de la práctica de los tribunales de justicia. En nuestra selección, como acabamos de anticipar, únicamente elegimos las voces y acepciones, en las que en el artículo lexicográfico se hallan comentarios, hechos por el autor, con los que suministra información sobre las circunstancias o restricciones de uso de ciertas piezas léxicas en el dominio forense y en varios campos del saber, o de actividades profesionales, de los cuales uno siempre es el forense (p. ej., "forense y comercio", "eclesiástico y forense", "forense y Gobierno", "forense y derecho", "en la práctica criminal y en lo forense", "tribunales, milicia y forense" ...). Por más que los casos, en los que se constata esta doble o triple 
adscripción, no sean numerosos, no resulta sencillo establecer un número "exacto" de los tecnicismos forenses: abonar ("término forense, y de comercio"), aceptación ("en lo forense, comercio, letras de cambio") y aceptación ("término de Jurisprudencia"), agravatorio ("término del Derecho, y Tribunales"), ejecutar ("en Tribunales, y entre Ejecutores, sacar alguna prenda, en que se traba la ejecución") y ejecutar ("en la Milicia y, en lo Forense, se dice de los suplicios, que se dan por orden de los Jueces"), emerjente ("en el Comercio, y Derecho"), eventual ("término de Leyes, lo que está fundado sobre alguna cosa incierta, o casual") y eventual ("se dice también el Derecho del que puede venir a alguno"), irregularidad ("en la Teolojía, y Derecho Canónico"), mejora ("en lo Forense y en el Derecho"), plenario ("en lo forense se dice del juicio posesorio, en que se trata del derecho de las partes, para la declaración de la posesión, o para el reconocimiento del derecho de propiedad") y plenario, ria ("en la práctica criminal se aplica al estado de la causa en que se recibe a prueba para la ratificación de testigos, y examen de otros nuevos, descargo del reo"), etc.

La estructura de los artículos sigue el esquema de la Academia, por lo que se refiere a la entrada (escrita en letras "versales"), y "cada acepción supone una entradilla nueva, según el modelo que siguió la Academia desde el Diccionario de autoridades" (Alvar Ezquerra 1987, I: IX), reproducida en letras "versalillas"; a diferencia del $D A$, no van acompañadas de la información gramatical ni se incorpora una base documental. Para señalar el dominio forense, Terreros no utiliza un mismo sistema, ni una única fórmula, o una abreviatura (for., como vemos en la tercera edición del diccionario académico), situada en el mismo lugar del artículo lexicográfico, perfectamente diferenciado de la definición. La falta de sistematicidad (puede verse "voz forense" o "en lo Forense") es evidente, si bien se constata más regularidad que en el $D A$, ya que, de modo casi general, la norma consiste en insertar las informaciones concretas de uso, inmediatamente después de la entrada o de la entradilla, separadas de éstas y de la definición (o de la equivalencia y de las remisiones) por una coma. Las fórmulas podemos reducirlas, grosso modo, a cuatro modelos: (a) "término forense" o "voz forense" (abdicación, abonar, acceptilación, aceptación, actualidad, acusar, enjuiciar, multar, oponer, petición, presuntivo, preventivo...), (b) "en lo forense" o "en el estilo forense" (aforar, ajuste, apremio, arraigar, arraigo, articular, asentamiento, concebir, declinatoria, defensoría, sin demora, interpelación ...), (c) "se dice en lo forense" o "se llama en lo forense" (coludir, delegación, mayorazguista, novelas, práctica, profecticios, reclamar, sobre-carta, subsidiario... ), y (d) "término que usan en lo forense" o "en lo forense es" (numerata pecunia, procurar...). De estas cuatro variantes, las más empleadas son "en lo forense" y "voz forense":

ABDICACIÓN, término forense, renunciación voluntaria de un cargo, renta, dignidad $[\ldots]$. 
ABONAR, término forense, y de comercio, salir por fiador de alguna cosa, darla por buena [...].

ACCEPTILACIÓN, voz forense: dícese de una paga finjida; [...].

ADMISIBLE, en lo forense, se dice de una demanda, prueba, testimonio [...].

COLUDIR, se dice en lo Forense por entenderse con alguna de las partes que pleitean, $[\ldots]$.

CONCEBIR, en el estilo Forense, y práctico se dice por expresar, o exprimir alguna cosa, [...].

NUMERATA PECUNIA, término que usan en lo forense. V. Contante.

PROFECTICIOS, se llaman también en lo forense, los bienes que provienen de los padres, $[\ldots]$.

SOBRE-CARTA, se llama en lo forense, una segunda carta, u orden que se da por algún Tribunal, [...].

Nuestro lexicógrafo construye una definición "suficiente" para el usuario, es escasa la disertación enciclopédica, no se ven apenas comentarios marginales o informaciones complementarias, y no suele indicar las fuentes (en ciertos ejemplos, y de modo excepcional, pueden hallarse envíos a una fuente documental o declaraciones sobre una determinada voz). Las remisiones las señala con la abreviatura $V$., con la que indica que la información correspondiente a esta entrada se encuentra en otro $u$ otros artículos:

ABULTAMIENTO, acción de abultar, término forense, V. Los Autos de las Comunidades de Toledo contra el Maestre-Escuela, sobre la asistencia a las funciones, y Circos, año 1758.

ACEPTACIÓN, en lo forense, comercio, letras de cambio, Beneficios eclesiásticos, \&c. el consentimiento del que recibe, aprueba, o admite alguna cosa. Fr. Acceptation, Lat. Acceptio. It. Accetazione. En términos de Teolojía se dice del modo de recibir las Constituciones del Papa, o de la acción con que se reciben. Hai aceptación tácita, y expresa.

ACTUALIDAD, voz forense, lo mismo que circunstancias presentes, V.

AFRONTAR, en lo forense, $V$. carear.

AJUSTE, en lo forense, V. Concordia, acomodación, convención, y pacto.

BENEFICIO DE INVENTARIO, en lo Forense, se dice de una herencia, o aceptación de ella con beneficio de inventario: de modo, que no se le puede obligar al heredero a pagar más deudas que las que permita la herencia. Del que miente mucho se dice: que se ha de recibir con beneficio de inventario lo que cuente. De un hombre que no tiene cosa alguna, se dice que no tiene oficio, ni beneficio [...].

LOÍSMO, voz forense, derecho que se paga al Señor del dominio directo de las ventas de las alhajas cargadas de censo perpetuo, o dadas a enfiteusis: en Castilla se paga uno de 50 del valor de la alhaja: en Valencia la décima: en Cataluña el tercio: en otras partes la veintena, y algunas veces se componen las partes [...] El Lat. Laudemium o laudimium, es de la baja latinidad. V. Valc. Agr. Jen. y Trev. \&c.

PRUEBA, V. Justificación, en lo forense.

QUEBRANTAR, en lo forense, casar, anular, rescindir. V.

REAMPARAR, voz forense, lo mismo que amparar, o protejer de nuevo. V. 
El diccionario, conforme se puede comprobar en los ejemplos reproducidos anteriormente, muestra una falta de regularidad tan notable en la microestructura, que dificulta la labor de establecer las características permanentes de cada uno de los elementos de que consta el artículo. Así, se documentan ejemplos en los que se presenta la definición, a continuación de la voz latina (proscripto); ejemplos en los que junto con la definición se pone la equivalencia en francés, latín e italiano (provisión, rebeldía), o sólo en francés y latín (recargo); ejemplos con advertencias de uso, la definición y las equivalencias en francés y latín (recondición), y se ven numerosas remisiones y equivalencias (reclamación, reclamo, reclamo, o reclamación), "inconsistencias" justificadas y lógicas en una obra de un único autor, cuya elaboración y redacción se prolonga durante veinte años:

PROSCRIPTO, en lo forense. Fr. Affiché. Lat. Proscriptus, el que está condenado a alguna pena por edicto público.

PROVISIÓN, en lo forense, la patente, letra, decreto, o cédula que se da para alguna ocupación o negocio. Fr. Provisions. Lat. Collati juris rescriptura. It. Provisione.

REBELDÍA, en lo forense no comparecer en juicio, siendo llamado, la acción de no comparecer. Fr. Etre en defaut, refus, faute de comparoir. Lat. Vadimonium desertum, nom obitum. It. Mancanza di comparire.

RECARGO, en lo forense, nuevo cargo que se hace al reo. Fr. Nouvelle charge, Lat. Novi criminis objectio.

RECLAMACIÓN, RECLAMO, en lo forense. V. Contraposición, demanda. Fr. Reclamation. Lat. Reclamatio, revindicatio, petitio, persecutio. It. Richiamo, domanda.

RECLAMO, O RECLAMACIÓN, en lo forense. Fr. Reclamation. Lat. Reclamatio, revindicatio, petitio. It. Richiamo.

RECONDICIÓN, voz forense, contrato segundo, después de cumplido el primero.

Fr. Renouvellement d'un bail. Lat. Renovatio, y otros reconductio.

El $D C C A$ hace una profunda revisión del vocabulario forense tanto en la nomenclatura como en los textos definitorios, puesto que "no sigue servilmente" el $D A$ (Álvarez de Miranda 1992: 568) y elabora definiciones propias. Aunque, en líneas generales, podamos admitir como válida la afirmación de que "todas las entradas de Autoridades están en Terreros, a veces con una grafía diferente" (Alvar Ezquerra 1987, I: XI) o que "es lógico también que toda la nomenclatura recogida en el primer diccionario académico pasara en bloque al del jesuita" (Álvarez de Miranda 1992: 568), se deben hacer dos precisiones de carácter general: (a) Terreros no recoge 59 entradas y entradillas y suprime estas indicaciones sobre el uso en 207 ejemplos, porque debe entender, acaso, que esa voz o acepción ya se ha trasvasado al léxico general, o porque considera que estas unidades léxicas deben ser catalogadas en otros campos de la ciencia o en otras actividades profesionales; y (b) el $D C C A$ mantiene esta información contextual en 116 unidades léxicas e incorpora a este dominio 113 "términos", que pueden ser palabras nuevas o palabras ya documentadas por el $D A$, pero que no mostraban esta clase de comentarios en la defini- 
ción. En los párrafos siguientes examinamos, en primer lugar, las entradas y entradillas suprimidas por el autor y las acepciones que no individualiza con una fórmula, y, en segundo lugar, las que sigue conservando del $D A$ y los "términos nuevos".

Las entradas y entradillas del $D A$ no seleccionadas por Terreros, que reproducimos como anexo en las últimas páginas de este estudio, las debió de excluir por tratarse de vocablos regionales o "provinciales", que el primer diccionario académico había restringido su uso al reino de Aragón (actitadero, actuario, albarán, alera, alifara, aprehenso, tríplica), por ser voces anticuadas o antiguas (aquende, deviedo, no embargante), o por no tener apenas uso en la lengua común de la España del siglo XVIII (abundamiento, acumulación, alargamiento). Tal vez proceda recordar que el $D R A E-1791$ elimina de la nomenclatura una forma compleja (acabarse la candela o candelilla), suprime la nota de uso en ocho (aprehenso, juramento de calumnia, cargos, caso negado, delegante, deviedo, sin embargo de embargos y confesión ficta) y no altera las restantes. A partir del "Prólogo" del jesuita no podemos explicar los motivos por los que hace desaparecer del DCCA tecnicismos, que han llegado hasta el $D R A E-1970$, la última edición en la que la institución usa la abreviatura for. para distinguir este dominio: cargos, delegante, obrar conforme a derecho, examinar testigos, ejecutante, ejecutorio, instituir heredero, pieza de autos, en rebeldía, retrovendición...

El número de entradas y entradillas, en las que suprime ${ }^{2}$ estas indicaciones en el artículo, porque debe suponer que forman parte del léxico general, alcanza la cifra de 207, es decir, el mismo número de tecnicismos forenses que hay que dejar de

2 Ejemplos en los que Terreros suprime las indicaciones de uso existentes en el DA: acción, achaque, actor, actuar, acumulador, acumular, adición, adjudicación, amortización, ampara, apercebimiento, aplicación de bienes, aprehensión, apropiar, apuntamiento, arbitrar, arbitrariamente, arrastrar, artículo, artículos, asentar, aserto, autor, dar o pedir favor y ayuda, bienes castrenses, bienes divisibles, bienes dotales, bienes enfitéuticos, bienes habidos y por haber, bienes mostrencos, bienes troncales, capitulaciones, castrense, causa, certificación, certificar, cesión de bienes, citar, civil, civilmente, comiso, comparecer, conato, concluir, conclusión, condenación, condición, confesión, consorte, constituyente, contento, contestación, contradictorio juicio, contraher, contumacia, contumaz, convenir en juicio, cuantía, curador, decir, declarar, declarar, declarante, decretar, decreto, defensión, defensor, definitivo, delegar, demandador, demandar, con denegación, denunciación, denunciar, deponer, deposición, derechamente, desembargar, deserción, despojar, detentación, determinar, devolución, devolver, dicho, dieta, discernimiento, discernir, donar, donatario, duplo, ejecución, emancipar, enalienable, entablación, enunciar, escribir, escrito, escriturario, espórtula, a prueba y estése, estipulación, estrechamente, excepcionar, expediente, expendedor, fama, fe, dar fe, foral, hecho, de hecho, ilegal, incompetencia, indeclinable, pro indiviso, informe, inquilino, insinuación, instalación, instalar, interlocutoriamente, interlocutorio, interrogatorio, intervención, legalizar, lesión, luctuosa, mandato, mantener, manumisión, manumisor, manutención, memorial ajustado, mutuo, negativo, obligación antidoral, oneroso, vía ordinaria, otorgar, pena ordinaria, perjudicial, pesquisa, prescripción, presunción, prevención, proceder, proceder, proceso, pronunciación, pronunciar, proscripción, protesta, protestar, proveer, pruebas, purgar, quebrantamiento, queja, quita, ratihabición, en rebeldia, recisión, reconocimiento, reconvención, recurso, recusar, 
contar. De nuevo sorprende que no coloque la fórmula en las definiciones de palabras simples, complejas o compuestas, que presentan en el DRAE-2001, si bien con la etiqueta Der. ('derecho'), particularidades del vocablo definido y circunstancias de uso restringidas a los dominios forense o jurídico: acción, actor, actuar, acumular, apercibimiento, apuntamiento, arbitrar, articulo, artículos, autor, bienes mostrencos, bienes troncales, capitulaciones, causa, certificar, cesión de bienes, citar, civil, civilmente, comiso, comparecer, conato, concluir, conclusión, condición, confesión, consorte, contestación, contumacia, contumaz, declarar, defensor, definitivo, demandar, deponer, deposición, desembargar, deserción, detentación, devolución, dieta, ejecución, escrito, estipulación, expediente, hecho, indeclinable, informe, interlocutoriamente, interlocutorio, lesión, mandato, manumisor, mutuo, otorgar, prescripción, presunción, proceder, proceso, pronunciar, protesta, proveer, purgar, quebrantamiento, queja, reconvención, recurso, recusar, reivindicar, relación, reponer, subdelegar, subrogar, substanciar, tercería, término, trámite, uso, venia, vía, vínculo...

Para establecer el conjunto citado, hemos tenido presente que en el texto de la definición del lema (o las acepciones) del DCCA no aparecen indicaciones, que permitan interpretar que ese vocablo tiene un uso restringido a lo forense, y que contamos cada acepción de un lema del DA (declarar, proceder, reponer) como aplicaciones autónomas de la 'forma semántica básica', pues los 'sentidos' de estos significantes corresponden a conceptos forenses diferentes:

DECLARAR. En lo forense se usa por determinar, decidir el juez o la persona que tiene jurisdicción para ello $(D A)$.

DECLARAR. Vale también en lo forense deponer, rectificar, decir debaxo de juramento el reo, testigo o perito en causa criminal o pleito civil $(D A)$.

DECLARAR alguna cosa obscura, oculta, \&c. Fr. Devinér. Lat. Detégere, indagáre, explicáre. It. Indevinare, scoprire (DCCA).

PROCEDER. Se toma también por entenderse alguna cosa, como perteneciente a la persona, o cosa que se trata. Úsase mucho en lo forense, y assí se dice: Esto no procede con Fulano $(D A)$.

PROCEDER. En lo forense es hacer causa a alguno, y formar processo contra él $(D A)$.

PROCEDER, verbo neutro, obras bien o mal. Fr. Proceder, agir. Lat. Procedere, se gerere. It. Procedere. El procedió bien en todo (DCCA).

REPONER. En lo forense vale volver la causa o pleito a su primer estado $(D A)$.

REPONER. En lo forense vale assimismo subrogar el Juez los derechos, acciones

reivindicación, reivindicar, relación, remisoria, remitir, repetición, reponer, reponer, reportar, representación, reproducir, retraher, revalidación, secrestar, solvente, subdelegación, subdelegar, subrogación, subrogar, substanciar, superveniente, tercería, término, título colorado, trabar ejecución, trámite, trance, transferir, transitivo, transmitir, troncal, uso, venia, ver, vía, vínculo, vindicación, vindicar, visto, voz. 
ganadas, o que se litigaban por alguno que murió, a otro que le representa, o tiene su derecho $(D A)$.

REPONER, volver a poner. Fr. Remettre. Lat. Reponere. It. Rimettere, riporre $(D C C A)$.

Otras piezas léxicas, como hemos reiterado, no muestran esta dimensión diasistemática existente en el $D A$, porque el autor las pasa a otros ámbitos de la ciencia o a otras actividades profesionales, y lo hace constar expresamente con notas del tipo "término de Jurisprudencia" o "se dice en la Jurisprudencia" o "en la Jurisprudencia" o "términos de jurisconsultos" (adminículo, adquirir, adventicios, agnación, aledaños, alimentos, alodial, aluvión, cancelación, cognático, comodato, cuasi-contrato, derecho, enajenable o alienable, estelionato, estipular, forma, homenaje, municipal, nuncupativo, parentesco, postilla, prescribir, preterido, primojenitura, prometer con juramento, querella, quirógrafo, al quitar, ratificación, recepticios, relajación, reversión, rogación o suplicación, sinalagmático, tajo, talión, testamento, título, tutela, unitivo, usucapión, dominio útil, vulnerario...), "en los Tribunales" o "en términos judiciales" (admisión, amonestar, copia, criminalizar, ejecutoria, expresar, hacer o dar fe, fuerza...), "término legal" o "término de leyes" o "en las leyes" o "voz de lejistas" (accesorio, acreedor, censo, enfiteosis o enfiteusis, eventual, heredar, indefensión, lejítimo, lejitimario, prevaricato, rédito, replicación, residencia...), y "término del Derecho" o "en el Derecho" o "voz del Derecho" (puede corresponder al derecho canónico, derecho civil, derecho eclesiástico, derecho público o derecho romano): abintestato, acceder, agravación, agravatorio, anticresis, autoridad, bígamo, capitulante, coactivo, coercitivo, coerción, concuasar, consentimiento, consistorio, dirimente, distinción, emerjente, eventual, expilación, extinctivo, formalidad, fundo, impetrante, imprescriptibilidad, imprescriptible, indotación, injenuidad, inoficiosidad, institución contra actual, interés de interés, interusorio, irregular, irregularidad, irritante, legado, liberto, causas mayores, motu proprio, naturalización, non obstancia, novación, policitación, postulación, precario, preterición, primitivos, profecticio, purgación canónica, redhibición, reivindicación, retrotracción, subjectivo, triente... No tomamos en consideración palabras del DCCA que el autor cataloga en el "comercio" (quita, redondeo), los "negocios" (ulterior) o clasifica como "voz de los escribanos" (protocolizar).

Es complicado determinar el número "exacto" de tecnicismos forenses, en los que Terreros mantiene ${ }^{3}$ esta restricción o especificidad de uso advertida por el $D A$, porque introduce variaciones y cambios importantes. Así, selecciona como lema el

3 Ejemplos en los que Terreros mantiene esta específica información existente en $D A$, si bien con variaciones: absolver de la instancia, aforar, afrontar, apercibir a uno, aprehender, aprehender, apremio, arraigar, arraigo, articular, asentamiento, atestar, auto, avocación o avocamiento, avocar, bajarse de la querella, beneficio de inventario, renunciar la cadena, caducidad, afianzar de calumnia, carear, 
verbo absolver (pero no incluye la forma compleja absolver de la instancia); reduce las tres acepciones del verbo aprehender a dos; selecciona como entrada avocación, o avocamiento y reclamo, o reclamación (en el $D A$ eran "lo mismo") y sustituye el cultismo de la forma compleja (lucro cessante) por la voz patrimonial (logro cesante), por ser de uso más frecuente en la lengua común:

ABSOLVER DE LA INSTANCIA. term. forense. Dar libertad al reo por falta de
probanzas, quedando pendiente la causa para continuar en ella siempre que las hu-
viere $(D A)$.

ABSOLVER, término Eclesiástico, y Forense, desatar, dar por libre de culpas, acusaciones o penas. Fr. Absoudre. Lat. Absolvere. It. Assolvere (DCCA).

APREHENDER. En lo forense vale, asir, agarrar y prender: y assí se dice el Juez aprehende a Fulano $(D A)$.

APREHENDER. También vale en lo forense entrar en la possessión, o tomar possessión $(D A)$.

APREHENDER. Vale conforme al dialecto de Aragón, Embargar bienes raíces. Es usado en lo forense $(D A)$.

APREHENDER, en lo Forense aprisionar, o prender, o agarrar. V. (DCCA).

APREHENDER, se dice asimismo en lo Forense, por lo mismo que tomar posesión. Fr. Saisir. Lat. In possessionem venire. It. Imparare. V. Apoderarse, tomar posesión, ocupar, dominar (DCCA).

AVOCACIÓN. s. f. Lo mismo que Avocamiento. Es voz forense $(D A)$.

AVOCAMIENTO. s. m. El acto de avocar alguna causa, u pleito, que se está litigando a otro Tribunal superior. Es voz forense $(D A)$.

AVOCACIÓN, o AVOCAMIENTO, término Forense, el acto de avocar a sí el Juez alguna causa. Fr. Evocation. Lat Avocatio, V. Avocar (DCCA).

LOGRO CESANTE, Y DAÑO EMERGENTE, términos forenses y de comercio, la ganancia, que se pierde, y daño que se sigue por tener en empréstido, \&c. algún caudal $(D C C A)$.

LUCRO CESSANTE. Term. Forense y Moral. Aquella ganancia que se discurría

cargo, casación, casar un instrumento, caución muciana, causante, traher a colación y partición, coludir, colusión, comodatario, compeler, complicidad, confitente, conocimiento, correo, dación, decisorio, declinar jurisdicción, deducir, defensoría, delegación, demanda, desapoderar, descargar, devolutivo, dilapidación, dilapidar, disculpación, divisorio, doblo, ejecutar, elidir, enjuiciar, espera, citar para estrados o señalar estrados, evicción, excursión, exhorto, falcidia, fallar, en grado de apelación, ilusorio, infirmar, información, inhibir, innovar, inoficioso, insolutundación, insolvente, instancia, interpelación, latitar, libelo, logro cesante, causa lucrativa, no ha lugar, masculinidad, mejora, mejorar la apelación, mora, novar, novelas, pedimento, petición, petitorio, plenario, prejudicial, preventivo, prorrogar la jurisdicción, prueba, quebrantar, quirografario, rebeldía, recargo, reclamación, reclamar, reclamo o reclamación, reo, reposición, reproducción, retracto, retrovender, revista, revistar, subsidiario, sumario, suplicar, taxativo, traspasación, tuición, tuitivo, turbativo, vientre, yusión. 
poder haberse adquirido en el tiempo que estaba parado el dinero dado por empréstido o mutuo: y se toma por razón para poder llevar interesses $(D A)$.

RECLAMO. En lo forense vale lo mismo que Reclamación $(D A)$.

RECLAMO, o RECLAMACIÓN, en lo Forense. Fr. Reclamation. Lat. Reclamatio, reivindicatio, petitio. It. Richiamo (DCCA).

El jesuita "rectifica" la información del $D A$, porque no "copia" los artículos del "extraordinario monumento" de la Academia. En el texto definitorio de 83 entradas y entradillas inserta ${ }^{4}$ fórmulas o advertencias, para destacar el uso de determinadas palabras en el campo forense; resume la definición; incluye remisiones y equivalencias en francés, latín e italiano; reelabora la explicación de algunas voces (así, abocar y avocar); incorpora nuevas acepciones marcadas (práctica), y modifica la lematización, entre otras razones, porque utiliza normas ortográficas diferentes a las de la Academia:

ABDICACIÓN. s. f. El acto de desheredarse en vida, o renunciar el puesto, dignidad, hacienda, u otra cosa $(D A)$.

ABDICACIÓN, término forense, renunciación voluntaria de un cargo, renta, dignidad, \&c. Fr. Abdication. Lat Abdicatio. It. Rinunziazione (DCCA).

ABOCAR. v. a. Convocar, o juntarse de concierto en algún sitio señalado para tratar, o hablar en algún negocio $(D A)$.

ABOCAR LA ARTILLERÍA. Ponerla derecha, y apuntarla a la parte, o sitio donde se quiere tirar $(D A)$.

ABOCAR en lo forense, en la milicia, artillería, \&c. abocarse. V. Avocar (DCCA).

ABONAR. v. a. Aprobar y dar por buena alguna cosa, y assegurarla por tal. Es voz compuesta de la partícula A, y de la palabra Bueno $(D A)$.

ABONAR, término forense, y de comercio, salir por fiador de alguna cosa, darla por buena. Fr. Pleiger. Lat. Fidejubére, Spondére. It. Mallevare. V. Fiar. (DCCA).

ACORDAR. v. a. Determinar, resolver uniformemente, y de común acuerdo, o por la mayor parte de votos, lo que se ha de hacer, o executar. Es voz freqüentemente usada en los Tribunales y Comunidades $(D A)$.

ACORDAR, voz forense, conceder esta, o la otra gracia. Fr. Accorder. Lat Concedere. It. Concedere (DCCA).

4 Ejemplos no marcados por el $D A$, en los que Terreros inserta fórmulas o advertencias sobre el uso son: abdicación, abocar, abonar, accesión, acensado o acensuado, aceptación, acordar, acriminar, actualidad, acusar, aherrojar, ajuste, allanamiento, aquiescencia, audiencia, averiguación judicial, caución juratoria, certidumbre, cierto, clientela, compeler, composición, concebir, concordia, confesante, contra-posición, contrario, convencido, crítica, cubrir, declaratorio, declinatorio, decretorio, demora, depredación, detención, estrado, exhibir, frustráneo, frustratorio, iniciar, intervenir, intestado, jurar y declarar, juratoria, justificación, materia, mayorazgo de masculinidad, mayorazguista, militar, moratoria, multar, numerata pecunia, oponer, oposición, pactar, plazo perentorio, posición, práctica, práctica, presuntivo, procurar, profecticios, proscripto, ratificar, acusar la rebeldia, refrendar, reintegrar, réplica, replicar, reprochar, resumen, sobre-carta, solemne, suposición, tenor, terminante, testadura, traba, vacaciones, vejación, vicioso, viripotente. 
AVOCAR. v. a. Llamar ante sí algún Tribunal superior, y traher los autos de alguna causa, citando las partes litigantes, y sacando el processo de otro Tribunal inferior. Es voz forense $(D A)$.

AVOCAR, en lo Forense, tirar, o traer a sí un Juez el conocimiento de una causa. Fr. Evoquér. Lat. Causam transferre, evocáre, avocáre. It. Avocare (DCCA).

PRÁCTICA. s. f. El exercicio, u actual execución, conforme a las reglas de algún Arte o Facultad, que enseña a hacer alguna cosa, como consiguiente a la theórica $(D A)$.

PRÁCTICA, en lo forense se dice de la ciencia de disponer bien un proceso, según las fórmulas de las ordenanzas y costumbres del país. Fr. Pratique. Lat Notitia rerum forensium. It. Notizia, cognizione della curia. Un Escribano debe saber la práctica, y un Abogado el derecho (DCCA).

PRÁCTICA, se dice asimismo de las minutas, libros o papeles que enseñan la práctica forense. Fr. Pratique. Lat. Litium instrumenta (DCCA).

Y, para finalizar, añade 33 voces o acepciones nuevas no documentadas por el DA: absolutorio, abultamiento, acceptilación, actualidad, admisible, ahijatorio, avogar, cabrevar, caso de privilejio, cesible, civilización, coludir, comparendo, conminatorio, contractual, convicto, daño emerjente, dar por cierta la apelación, sin demora, depredación, detentor, exculpación, loismo, obventicio, perención, preinserto, recisorio, recondición, replicato, rescindir, resultante, fianza in sólidum $\mathrm{y}$ vigorizar.

\section{CONCLUSIONES}

En las páginas anteriores hemos estudiado el dominio forense en el $D C C A$ y hemos hecho un cotejo con el $D A$ "la fuente principal de Terreros". Las conclusiones, en virtud de la problemática que hemos expuesto, tienen que ser, necesariamente, provisionales, máxime cuando en cada nueva lectura del $D A$ pueden descubrirse más tecnicismos forenses.

$\left.1^{a}\right)$ Cuando se estudia esta clase de tecnicismos, no se puede prescindir de principios generales del Derecho, existentes en las grandes obras de la historia del derecho español, que son a la vez monumentos de la historia de la lengua española y fuentes importantes de las obras lexicográficas, como el Fuero Juzgo o Las Siete Partidas. En la traducción al romance castellano del código visigodo, hecha por un autor desconocido en la primera mitad del siglo XIII, se ordena que "el fazedor de las leyes deve fablar poco, e bien; e non deve dar iuyzio dubdoso, mas lano, e abierto, que todo lo que saliere de la ley, que lo entiendan luego todos los que lo oyeren, e que lo sepan sin toda dubda, e sin ninguna gravedumbre" (Fuero Juzgo, lib. I, tít. I, ley VI) y el mismo "deber" o imperativo legal se constata en la compilación del Rey Sabio:

Cumplidas deven ser las leyes, e muy cuydadas, e catadas, de guisa que sean con razón, e sobre cosas que puedan ser, segund natura, e las palabras dellas que sean bue- 
nas e llanas e paladinas, de manera que todo hombre las pueda entender e retener. E otrosí, an de ser sin escatima e sin punto: porque no puedan de el derecho sacar razón tortizera: por su mal entendimiento, queriendo mostrar la mentira por verdad: o la verdad, por mentira: e que no sean contrarias las unas de las otras (Primera partida, tít. I, ley VIII).

Como se desprende de las dos citas anteriores, el iuyzio, que el $D A$ (s. v. juicio) describe como "conocimiento de causa, en la qual el Juez ha de pronunciar sentencia, distinguiendo el derecho de las partes" y "se toma también por la misma sentencia, especialmente quando es castigo", no puede ser dudoso, sino claro, "que lo entiendan todos", para que lo sepan "sin duda" y "sin dificultad" (gravedumbre) y las palabras de las leyes tienen que ser llanas ("fáciles, corrientes") y paladinas ("claras y patentes"), para que todos las puedan entender. Estas normas ayudan a explicar el hecho de que muchos tecnicismos forenses sean voces del léxico común (con acepciones técnicas), por ello es difícil establecer en este campo de la ciencia o actividad profesional una línea divisoria clara entre el léxico común y el léxico especializado.

$2^{\mathrm{a}}$ ) Aunque Covarrubias, cuando tiene que describir palabras con valor especializado, remite a los especialistas, registra en su obra más de 250 tecnicismos forenses y jurídicos (Henríquez 2005). Y a pesar de lo que se diga en el prólogo, el primer diccionario académico "incluye miles de tecnicismos" (Gutiérrez Rodilla 2003: 458), de los cuales 458 son del dominio forense (Henríquez 2004); y a mayor abundamiento, el $D R A E-1791$, aunque lleva a cabo una "censura" de las voces y corrige los "defectos" del $D A$, contiene 512 tecnicismos forenses (Henríquez 2006). Por ello, hay que acabar con el tópico de que los diccionarios generales monolingües desatienden los tecnicismos forenses, pues los datos empíricos demuestran todo lo contrario: estas obras ponen a disposición de los lectores una información inestimable para reconstruir la historia de la terminología del Derecho.

$3^{\text {a) }}$ El DCCA de Terreros es lógico que supere el corpus académico, ya que lo toma como referente, pero el autor se preocupa más por acumular "términos", que por describir y explicar ese ingente caudal de voces, que con tanta paciencia y dedicación ha ido recogiendo a lo largo de esos veinte años, que dedicó a la elaboración de su obra. Los fundadores de la Real Academia Española habían explotado ampliamente el caudal y las definiciones del Tesoro (Seco 2003: 198) y Terreros va a proceder del mismo modo con el $D A$, pero de las 31 voces técnicas, que Covarrubias marcaba con la etiqueta forense, solamente mantiene 11 (caso, caución, colusión, conocimiento, declinar, innovar, instancia, plazo, prueba, rebeldía y vista) y reduce los 458 tecnicismos forenses del $D A$ prácticamente a la mitad.

$4^{\text {a }) ~ N o ~ d e j a ~ d e ~ s e r ~ u n ~ o b s t a ́ c u l o ~ i m p o r t a n t e, ~ p a r a ~ c o n o c e r ~ m e j o r ~ e s t a ~ p a r c e l a ~ d e l ~}$ léxico del $D C C A$, que Terreros, en ningún pasaje de su extenso prólogo especifique o aclare cómo ha recogido el vocabulario del dominio forense, ni nos diga las obras 
de los especialistas que consultó, ni nos facilite información sobre si ha recopilado algunas de estas voces a través de entrevistas con jueces, abogados u otros profesionales del campo del derecho, que eran "personas juiciosas y sabias".

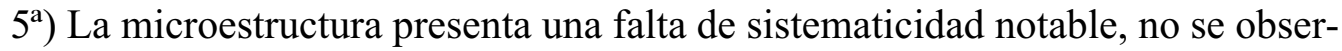
van características constantes para cada uno de los elementos de que consta el artículo, las definiciones son "suficientes" para los usuarios, pero se abusa de las remisiones y de las equivalencias, y casi no se ven comentarios marginales o informaciones complementarias. Constituyen "carencias" importantes que nuestro lexicógrafo no inserte información gramatical a continuación de la entrada y que no aporte una base documental.

$\left.6^{a}\right)$ El $D C C A$ es, a pesar de lo dicho, una obra de gran interés lexicográfico, lexicológico e histórico, que hay que analizar dentro de la época, en la que le tocó vivir al autor, y en el marco de las específicas circunstancias biográficas del jesuita. Es la obra original de un único autor, que no "copia"; en el caso de que reproduzca más o menos fielmente el $D A$, comprueba los datos y puede rectificar la información, pero no alcanza el rigor lexicográfico, etimológico o histórico del primer diccionario académico. Terreros es un claro ejemplo de humildad, de honradez, de paciencia, es un trabajador incansable, que realiza consultas bibliográficas e investigación de campo, virtudes y cualidades imprescindibles para llevar a cabo cualquier obra lexicográfica: "yo oiré con gusto a quien con amistad, penetración y conocimiento me advierta de los hierros que pueda haber cometido, y más si hubiere tenido que poner la mira en 180.000 términos que regulo por buena cuenta en la diversidad de acepciones de las voces y modos de hablar que traigo" (Terreros 1987, I: XXXIV).

\section{REFERENCIAS BIBLIOGRÁFICAS}

Alvar Ezquerra, M. (1987 [1786-1793]): “Presentación”, en E. Terreros y Pando, Diccionario castellano con las voces de ciencias y artes y sus correspondientes a las tres lenguas francesa, latina e italiana, Madrid, Arco/Libros, ed. facsímil, pp. V-XVI.

Ahumada, I. (2000): "Diccionarios de especialidad en los siglos XVIII, XIX y XX", en Cinco siglos de lexicografía del español, IV Seminario de Lexicografía Hispánica (Jaén, 17 al 19 de noviembre de 1999), Jaén, Universidad de Jaén, pp. 80102.

Alfonso X (1605): Las Siete Partidas del Sabio Rey don Alonso el nono, nuevamente glosadas por el Licenciado Gregorio López del Consejo Real de Indias de su Magestad, Salamanca, por Andrea de Portonaris.

Álvarez de Miranda, P. (1992): "En torno al Diccionario de Terreros", Bulletin Hispanique, 94,2 , pp. 559-572. 
(2001): "Los jesuitas españoles expulsos. Su imagen y su contribución al saber sobre el mundo hispánico en la Europa del siglo XVIII", en Actas del coloquio internacional de Berlín (7-10 de abril de 1999), ed. de Manfred Tietz en colaboración con Dietrich Briesemeister, Frakfurt-Madrid, Vervuert-Iberoamericana, pp. 44-73.

Azorín Fernández, D. (2000): “Terreros y Pando y la recepción de los tecnicismos en los diccionarios generales del español (siglos XVIII-XIX)", en Los diccionarios del español en su perspectiva histórica, Alicante, Universidad de Alicante, pp. 201-227.

CATAlÁ Torres, N. (2003 [1611]): "Los problemas referentes al lenguaje científico en los diccionarios de uso", en B. Gutiérrez Rodilla, ed., Aproximaciones al lenguaje de la ciencia, Burgos, Fundación Instituto Castellano y Leonés de la Lengua, pp. 499-523.

Covarrubias, S. DE (2003): Tesoro de la lengua castellana o española, ed. de M. de Riquer, Barcelona, Alta Fulla.

DA. Real Academia Española (1990 [1726-1739]): Diccionario de Autoridades, Madrid, Gredos, ed. facsímil.

DCCA. E. TeRreros y PANDO (1987 [1786-1793]): Diccionario castellano con las voces de ciencias y artes y sus correspondientes a las tres lenguas francesa, latina e italiana, edición facsímil y estudio preliminar de M. Alvar Ezquerra, Madrid, Arco/Libros, 4 vols.

DRAE-1791. ReAl ACADEMIa ESPañola (17913): Diccionario de la lengua castellana reducido á un tomo para su mas fácil uso, Madrid, Viuda de Don Joaquin Ibarra.

DRAE-1970. Real ACADEMIa Española (1970 $\left.{ }^{19}\right)$ : Diccionario de la lengua española, Madrid, Espasa-Calpe.

DRAE-2001. Real ACADEMia Española (200121): Diccionario de la lengua española, Madrid, Espasa.

ECHEVARRÍA IsusquizA, I. (2001): "El autor en el Diccionario de Terreros", en M. Maquieira Rodríguez, M. Martínez Gavilán y M. Villaverde Llamazares, eds., Actas del II Congreso Internacional de la Sociedad Española de Historiografía Lingüistica, Madrid, Arco/Libros, pp. 371-384.

Fuero Juzgo (1815): Madrid, Ibarra [ed. facsímil, Valladolid, Lex Nova, 1990].

García Platero, J. M. (2003): "La lexicografía no académica en los siglos XVIII y XIX”, en A. M. Medina Guerra, coord., Lexicografía española, Barcelona, Ariel, pp. 263-280.

GutiÉRrez Rodilla, B. (2003): "Los diccionarios, instrumentos importantes en la reconstrucción del lenguaje científico", en B. Gutiérrez Rodilla, ed., Aproxima- 
ciones al lenguaje de la ciencia, Burgos, Fundación Instituto Castellano y Leonés de la Lengua, pp. 453-463.

HAENSCH, G. (1997): Los diccionarios del español en el umbral del siglo XXI, Salamanca, Universidad de Salamanca.

Henríquez Salido, Ma do C. (2004): "La marca 'forense' en el Diccionario de Autoridades", en C. Corrales Zumbado et al., eds., Nuevas aportaciones a la historiografia lingüistica. Actas del IV Congreso internacional de la SEHL (La Laguna, 22 al 25 de octubre de 2003), Madrid, Arco/Libros, I, pp. 761-771.

_ (2005): "Para una historia de la lengua de la ciencia: el vocabulario jurídico en el Tesoro de Covarrubias", Revista Portuguesa de Humanidades, 9, pp. 79-115.

(2006): "La calidad y censura de las voces en el DRAE-1791: la marca 'forense"”, en J. I. Pérez Pascual y M. Campos Souto, eds., El diccionario de la Real Academia Española: ayer y hoy, A Coruña, Universidade da Coruña, pp. 139151.

SeCo, M. (2003²): Estudios de lexicografía española, Madrid, Gredos.

ANEXO. VOCES, ACEPCIONES Y FORMAS COMPLEJAS DEL DOMINIO FORENSE REGISTRADAS POR EL $D A$ NO DOCUMENTADAS EN TERREROS

ABUNDAMIENTO. s. m. Lo mismo que abundancia. Véase. Esta voz en el sentido recto no tiene ya uso, pero en lo legal y forense es mui común, y significa comprobación, afirmación, resguardo y seguridad: y siempre se usa con la palabra mayor, antepuesta, diciendo: A mayor abundamiento.

ACABARSE LA CANDELA O CANDELILLA. Es estar cerca el remate de algún arrendamiento, postura, o venta, que se hace públicamente, en que según estilo se encienden tres candelas o velas sucessivamente por el pregonero: y en acabándose la última, sino hai quien puje u dé más por la alhaja o renta, que se está vendiendo, arrendando, y rematando, se entiende que queda rematada por el último postor. Es voz forense.

ACTITADERO, RA. adj. Término forense, que solo tiene uso en el Reino de Aragón, y significa lo que está por actuar, o actitar: como una causa, o processo, que está mui a los principios, y en que apenas se ha empezado a actuar.

ACTUARIO (Actuário) s.m. El escribano, o Notario ante quien passan las causas. Es voz que solo tiene uso en lo forense en el Reino de Aragón.

ACUMULACIÓN. s.f. La Junta de varias cosas. En lo literal tiene poco uso; pero en lo forense es mui freqüente para significar el agregado de diferentes autos, causas, y processos, lo que se hace por mandado de Juez, y se llama auto de acumulación. 
ALARGAMIENTO. s. m. El acto de alargar alguna cosa. Es voz que tiene poco uso, y solo en el estilo forense se practica comúnmente.

ALBARÁN. Vale también obligación hecha sin Notario, o Escribano a favor de alguno, por débito, u otra qualquiera causa, o caso, como lo es un vale o papel firmado. Es término forense usado en Aragón.

ALERA. Vale también en el estilo forense de Aragón el derecho de poder apacentar el ganado los vecinos de un lugar en los términos o territorio que hai desde las eras de él hasta las de los lugares circunvecinos, como sea de sol a sol, y de suerte que saliendo de las eras de un lugar con sol, pueda volverse a ellas antes de ponerse.

ALIFARA. s. f. Voz forense y antiguadamente usada en Aragón, y significa comida, u dinero para ella, que el que compraba daba al que vendía demás del precio de la cosa comprada, sin lo qual no era válida la escritura de venta.

AMORTIZAR. v. a. Es poner una hacienda en poder de alguna persona, o Comunidad Eclesiástica, que de allí adelante no se puede vender, y queda como muerta, sin pagar derechos, ni alcabalas. Es voz forense.

APREHENSO, SA. part. pas. del verbo Aprehender en el significado de seqüestrar y embargar: y vale lo mismo que seqüestrado y embargado, hablando de bienes raíces, según el uso curial y forense de Aragón.

AQUENDE. adv. Vale tanto como de esta parte. Es voz antigua, y que solo tiene uso en el estilo forense.

CADUCAR EL LEGADO, O EL FIDEICOMISSO. Phrase forense. Resolverse la constitución de él, conforme a lo ordenado por el fundador.

CAER EN COMISSO. Phrase forense, que se dice de las mercaderías que son de contrabando, o passan sin registro; y también del Emphiteuta, que no cumple con lo capitulado en la fundación del emphiteusis, o censo perpetuo.

Juramento de calumnia. Se llama en lo forense el que hace el actor para justificar su buena intención en poner o seguir el juicio, y que no es malicioso: y se hace para evitar la calumnia.

CARGOS. También en lo forense se llaman assí en las residencias, o visitas de los Jueces, las faltas que resulta haver cometido durante su gobierno. De estos los unos se llaman generales, quando son contra la observancia de las leyes económicas de la República, y otros especiales o particulares, quando son por defecto en la administración de justicia.

CASO NEGADO. term. forense. Lo mismo que Concedido sin perjuicio; y assí, quando una cosa se propone para disputarla y refutarla, en caso que pudiesse ser cierta o legítima para proceder en su averiguación y certidumbre, se dice como presupuesto.

Hacer la causa. Phrase forense. Formar el processo al reo del delito que ha cometido para acusarle por lo que consta de él y darle la sentencia.

CITAR DE REMATE. Hacer saber, notificar al deudor executado el remate. Es phrase forense.

Dar la causa por conclusa. En el estilo Forense es no haver ya más que alegar en algún pleito o causa, y darle por fenecido para que el Juez pronuncie la sentencia. 
Juicio contencioso. Phrase forense. El pleito en que se disputa del derecho entre partes.

DAR FIADOR, O FIANZA. Term Forense, que significa presentar ante el Juez sugeto, y bienes, que estén obligados a la paga, en caso de faltar el principal a su obligación.

DAR QUERELLA. Term. Forense, que vale Presentar ante el Juez petición, en que se alega de agravios y se pide satisfacción contra alguno que se ha ofendido en la honra, vida o hacienda.

DELEGANTE. part. act. del verbo Delegar. La persona que delega, o comete sus veces o jurisdicción. Tiene uso en lo forense.

Obrar conforme a derecho. Phrase forense con que los Tribunales superiores advierten a los inferiores atiendan a la justicia de las partes, procediendo en todo con la rectitud que se debe.

DESAMPARAR LA APELACIÓN. Phrase forense, que significa declararla por desierta.

DESAMPARAR SUS BIENES. En lo forense es hacer dexación de ellos, para evadir la molestia de los acreedores.

DEVIEDO. s. m. Deuda o pena contrahída por prohibición, delito u rebeldía. Es voz antigua, que solo tiene uso en lo forense en algunos juzgados, como son los de los Molares o Pedáneos, que condenan en uno o más deviedos. Tráhela Covarr. en su Thesoro.

DEXACIÓN DE BIENES. La cessión que hace de ellos el deudor quando la suma de las deudas excede al capital o valor pronto de los bienes: consiguiendo por este medio eximirse de la prisión, o molestia que le puede hacer el acreedor. Es término Forense.

No embargante. Modo adverbial. Significa lo mismo que No obstante, sin embargo. Es término mui usado en lo forense, aunque ya algo antiquado, por prevalecer más los términos Sin embargo, y No obstante.

Sin embargo de embargos. Phrase adverbial, usada en lo forense, por la qual manda el Juez competente se pague el libramiento que da de los bienes, u dinero que está embargado por él, o recargado por otros Jueces, o acreedores, sin que le obste esta circunstancia, ni se resista el depositario a recoger el referido libramiento y satisfacer la cantidad que contiene.

ENORMÍSSIMA. s. f. Term. forense. La lesión y fraude que se comete en las ventas y contratos, quando hai excesso en más de la mitad del justo precio que valía.

ESTRECHAR LOS TÉRMINOS. En lo forense. Acortar y abreviar los términos y tiempos, para concluir quanto antes las causas, y ponerlas en estado de sentencia, quando se rezela o teme algún daño y perjuicio grave, o conviene al estado de ellas.

Sin estrépito o figura del juicio. Phrase forense, con que se explica que en algunos pleitos o causas se procede sin observar las formalidades y solemnidades de derecho: sino de plano, breve y sumariamente.

EXAMINAR TESTIGOS. En lo forense es tomarles las declaraciones, y escribir lo que dicen y deponen al tenor del interrogatorio de las preguntas.

EXECUTANTE. part. act. del verbo Executar. El que executa judicialmente a otro por la paga de algun débito. Es usado en lo forense.

EXECUTORIO, RIA. adj. Term. forense. Lo mismo que Executivo en el significado de poner por obra lo mandado executar por Juez competente. 
Confessión ficta. Se llama en lo forense la convención que resulta de la entera negación del reo.

GENERALES DE LA LEY. Se llaman en lo forense las tachas o excepciones que la ley tiene señaladas contra los testigos, como la menor edad, amistad, o parentesco con las partes, interés en la causa, \&c.

IMPOSICIÓN DE PERPETUO SILENCIO. Phrase forense con que se prohíbe al actor, el que jamás vuelva a deducir la acción, o a instar sobre ella.

Causar instancia. Phrase forense, que significa exercitar la acción en juicio por el término y con las formalidades establecidas por el derecho.

Sin causar instancia. Phase forense, con que se protesta, que no se quiere seguir juicio formal.

INSTITUIR HEREDERO. En lo forense, es declararle o nombrarle, para que suceda en los derechos del difunto.

Testigos instrumentales. En lo forense son los que assisten al otorgamiento del instrumento.

JURAMENTO SUPLETORIO. En lo forense es el que se pide a la parte, para suplir la falta de prueba legal.

NOTORIEDAD DE DERECHO. Se llama en lo forense la pública noticia que resulta de la sentencia dada en algún caso, particularmente criminal.

PIEZA DE AUTOS. En estilo forense se llama el conjunto de papeles cosidos, pertenecientes a una causa.

De plano. En lo forense es el modo de proceder, en que se dispone un processo, excusando muchas formalidades judiciales.

PURGAR LA INFAMIA. Phrase forense, que se dice del reo cómplice en un delito, que habiendo declarado contra su compañero, no se tiene por testigo idóneo, por estar infamado del delito, y poniéndole en el potro del tormento y ratificando allí su declaración, se dice que purga la infamia, y queda válida la declaración.

REASSUMIR LA JURISDICCIÓN. Phrase forense, que vale suspender el superior, o quitar por algún tiempo la jurisdicción que otro tenía, tomándola en sí, para poder proceder y conocer en algún negocio, con todas las circunstancias y solemnidades que se necessita.

En rebeldía. Modo adverb. que en lo forense explica, que citado el reo, y no compareciendo, se le hace presente para la prosecución y sentencia de la causa.

RECONDUCCIÓN. s. f. term. forense. El contrato de segundo arrendamiento, que se celebra con alguno, después de cumplido el tiempo del primero.

REINTEGRACIÓN DE LA LÍNEA. Se llama en lo forense el tránsito que hacen los Mayorazgos, quando vuelven la sucessión a aquella línea, que quedó privada o excluida, por faltarle la qualidad deseada por el Fundador, o por otro qualquier motivo.

RETROVENDICIÓN. s. f. Term. forense. El acto de retrovender.

Estar a juzgado y sentenciado. Phase forense, que vale quedar obligado a oír y consentir en la sentencia, que se diere. 
TRÍPLICA. s. f. Petición que se da respondiendo a la segunda contradición del contrario. Es voz forense usada en Aragón.

Término ultramarino. En lo forense se llama el que se concede para la prueba, proporcionado a la distancia donde se ha de hacer; a diferencia del legal de ochenta días.

USAR DE SU DERECHO. Phrase forense, que significa valerse de la acción, que a cada uno le compete para el efecto, que le convenga: y por extensión vale usar de su libertad lícitamente en qualquier línea.

Indicios, o sospechas vehementes. Llaman en lo forense aquellos que mueven de tal modo a creer reo de algún delito a alguno, que ellos solos equivalen a semiplena probanza. 